\title{
Crisis económica frente a crisis matrimonial: los tribunales ante los nuevos modelos familiares
}

Elisa Muñoz-Catalán*

Doctora en Derecho, Universidad de Huelva. Profesora acreditada, Universidad de Huelva, Huelva, España. Correo electrónico:

elisa.munoz@dthm.uhu.es

Recibido: 20 de marzo del 2015

Aprobado: 25 de mayo del 2015

Cómo citar este artículo: Elisa Muñoz-

Catalán. Crisis económica frente a crisis matrimonial: los tribunales ante los nuevos modelos familiares. DIXI 22. Diciembre 2015 .

Pág. 11. doi: http://dx.doi.org/10.16925/ di.v17i22.1246

\section{Resumen}

Introducción: desde la aprobación del Código Civil español en el siglo XIX, España ha experimentado importantes y numerosas transformaciones jurídico-sociales. Estas no sólo han afectado el Derecho de familia en general, sino también - y especialmente- la regulación del matrimonio y los nuevos modelos familiares con respecto a sus consecuencias ante situaciones de crisis matrimonial. Metodología: en este sentido, este artículo de investigación parte de las novedades legislativas existentes en esta materia, introducidas en las últimas décadas a fin de examinar el alcance de diferentes sentencias en las cuales, en efecto, se pone de manifiesto cómo los tribunales civiles, ante la situación de crisis económica generalizada, tratan de adaptarse a la nueva realidad social y otorgan un papel esencial a los abuelos ante un proceso de nulidad, separación o divorcio. Conclusiones: de igual forma, se analiza cómo incluso permiten en situaciones excepcionales - e.g. la que se pone de manifiesto en la reciente Sentencia del 2 de marzo del 2015-, a aquel progenitor separado, en paro y que viva de manera persistente en la pobreza, no hacer frente a la pensión alimenticia que venía abonando a sus hijos hasta entonces, ni siquiera abonando el denominado "mínimo vital" (esto hasta que encuentre los recursos necesarios para su subsistencia).

Palabras clave: crisis, familia, matrimonio, menores, pensión, tribunales. 


\title{
Economic Crisis in a Context of Marital Crises: the Courts in the Context of New Family Models
}

\begin{abstract}
Introduction: Starting with approval of the Spanish Civil Code in the $19^{\text {th }}$ century, Spain has experienced significant and numerous legal and social transformations. These have not only affected family law in general but also, and particularly, the regulation of marriage and the new family models in terms of their consequences in situations of marital crisis. Methodology: In that sense, this research article looks at existing legislative innovations in the field, introduced in recent decades, with the aim of examining the scope of different rulings that effectively show how the civil courts, faced with a situation of widespread economic crisis, try to adapt to the new social reality and award an essential role to grandparents in processes of nullification, separation or divorce. Conclusions: It also analyzes how in exceptional situations, for example in the recent ruling of March 2, 2015, separated parents who are unemployed and live in persistent poverty are permitted to stop paying child support without even paying the so-called "vital minimum" until they are able to obtain the necessary funds for subsistence.
\end{abstract}

Keywords: crisis, family, marriage, minors, pension, courts.

\section{A crise econômica ante a crise matrimonial: os tribunais diante dos novos modelos familiares}

\section{Resumo}

Introdução: desde a aprovação do Código Civil espanhol no século XIX, a Espanha experimentou importantes e numerosas transformações jurídico-sociais. Estas não somente afetaram o direito de família em geral, mas também -e especialmente- a regulação do matrimônio e dos novos modelos familiares com respeito a suas consequências diante de situações de crise matrimonial. Metodologia: nesse sentido, este artigo de pesquisa parte das novidades legislativas existentes nessa matéria, introduzidas nas últimas décadas a fim de examinar o alcance de diferentes sentenças as quais, na verdade, mostram como os tribunais civis, diante de situação de crise econômica generalizada, tentam adaptar-se à nova realidade social e outorgam um papel essencial aos avós diante de um processo de anulação, separação ou divórcio. Conclusões: igualmente, analisa-se como, inclusive, permitem em situações excepcionais -e. g. que aparece na recente Sentença de 2 de março de 2015-, àquele progenitor separado, sem trabalho, e que viva de maneira persistente na pobreza, não se responsabilizar pela pensão alimentícia que vinha abonando a seus filhos até então, nem sequer abonando o denominado "mínimo vital" (isso até que consiga os recursos necessários para sua subsistência).

Palavras-chave: crise, família, matrimônio, menores, pensão, tribunais. 


\section{INTRODUCCIÓN}

Tras diez años desde la aprobación en España de la Ley $13 / 2005,{ }^{1}$ por la que se modifica el Código Civil (CC) en materia de derecho a contraer matrimonio, y ante los tiempos de crisis económico-social que se viven, resulta necesario profundizar comparativa y globalmente sobre la manera en que ha evolucionado en las últimas décadas la interpretación judicial de las diversas cuestiones controvertidas que subyacen a todo proceso de nulidad, separación o divorcio.

Un ejemplo de las premisas sobre las que parte este estudio se encuentra en la reciente sts del 2 de marzo de 2015. ${ }^{2}$ En esta, ante situaciones de crisis matrimonial y con la finalidad de que los hijos tengan cubiertas sus necesidades básicas de alimentación, educación, vivienda, vestimenta, etc., si bien se reitera la doctrina del tribunal respecto a la necesidad de cumplir con el denominado "mínimo vital" (calculado en unos 150 a 200 euros), lo cierto es que, de manera novedosa y con un carácter marcadamente excepcional, se exonera al progenitor desempleado de abonar la pensión alimenticia que venía pagando hasta entonces. Siempre y cuando, eso sí, que este acredite una falta continuada y persistente de ingresos o recursos que lo lleven a una situación de pobreza extrema. $^{3}$

Por lo anterior, la aplicación de las normas procesales generales a los procesos civiles y, en especial, al proceso matrimonial ha puesto de relieve en estos últimos años lagunas, desajustes e insuficiencias que se observan en la práctica. Todas las cuales motivadas sobre todo por la propia naturaleza del proceso matrimonial, la dinámica de la vida familiar y las constantes modificaciones en relación con las situaciones de crisis matrimonial.

El objeto del proceso matrimonial presenta unos rasgos particulares y una dinámica propia que producen un choque frontal $a b$ initio ("desde el inicio") respecto al esquema procesal habitual, y en relación

1. Véase Ley 13/2005. Por la que se modifica el Código Civil en materia de derecho a contraer matrimonio. Julio 2 de 2005. BOE N. ${ }^{\circ} 157$.

2. Tribunal Supremo. Sentencia 138/2015. (M. P. Rafael Sarazá Jimena; Marzo 24 de 2015). Disponible en http://s01.s3c.es/imag/ doc/2015-04-16/STSs_ClausulaSuelo.pdf

3. Antonio Contreras. El delito de impago de pensiones alimenticias. Breve guía jurídica, artículos doctrinales. Noticias Jurídicas. Julio 7 de 2014. Disponible en http://noticias.juridicas.com/conocimiento/articulos-doctrinales/4895-el-delito-de-impago-de-pensiones-alimenticias-breve-guia-juridica/ con los principios de preclusión y cosa juzgada. Así, es posible decir que lo anterior se debe esencialmente, por un lado, a la vivacidad de los conflictos y, por otro, a la necesidad de valorar situaciones nuevas de origen objetivo y/o subjetivo. ${ }^{4}$

Resulta evidente que ni las normas específicas ya recogidas en las "Disposiciones Adicionales" de la Ley $30 / 1981,{ }^{5}$ en relación con el procedimiento a seguir en las causas de nulidad, separación o divorcio, ni las normas procesales generales establecidas en los artículos 919 y siguientes de la Ley de Enjuiciamiento Civil 1/2000 (LEC), ${ }^{6}$ son suficientes en la actualidad para considerar plenamente regulado el cauce procesal de estas reclamaciones derivadas de la situación de crisis en la convivencia conyugal. Motivo por el cual se ha de completar con la jurisprudencia de los tribunales al aplicar caso por caso.?

La aportación jurisprudencial que a continuación se analiza detalladamente permite conocer cuál ha sido, en los últimos tiempos, la actuación de los tribunales españoles al resolver estos procesos y de qué manera se trata de proteger los intereses de las partes implicadas - o incluso de terceros ${ }^{8}$ - a la hora de cumplir la decisión final del juez. De esta manera,

4. En relación con las situaciones objetivas, se destacan las derivadas de la mayoría de edad o la ocupación laboral. Y aquellas de origen subjetivo se dan con frecuencia para casos relativos a la guarda y custodia del menor o incapacitado y las actitudes frente a responsabilidades paternofiliales.

5. Véase Ley 30/1981. Por la que se modifica la regulación del matrimonio en el Código Civil y se determina el procedimiento a seguir en los casos de nulidad, separación, y divorcio. Julio 20 de 1981. BOE N. ${ }^{\circ} 172$. 6. Ley 1/2000. Ley de Enjuiciamiento Civil. Enero 7 de 2000. вов N. ${ }^{\circ} 7$.

7. Véase Auto de la Audiencia Provincial de Málaga de 10 de marzo de 2004; Sentencia de la Audiencia Provincial de Granada del 30 de junio de 2001 (doctrina relativa a los procesos de filiación: en la LEC $1 / 2000$, el principio de libre investigación de la paternidad si bien constituye una prueba biológica en la que la negativa a someterse a ella no implica "ficta confessio", sí que en cambio es un indicio valioso que permite ubicar el Derecho de Familia en la actualidad en normas de ius cogens).

8. Cf. Ley 42/2003. De modificación del Código Civil y de la Ley de Enjuiciamiento Civil en materia de relaciones familiares de los nietos con los abuelos. Noviembre 21 de 2003. вов N. ${ }^{\circ} 280$. Esta ley se encuentra en relación con la importancia de la figura de los abuelos a la hora de favorecer la situación de los nietos que queden desprotegidos por la ruptura conyugal. Para ello, se hace preciso constatar la voluntad de los abuelos con el fin de asumir las obligaciones que serían propias de sus padres en situaciones normales, y que en estos casos, actúan de forma subsidiaria para cubrir las obligaciones inherentes a los progenitores. Observa, de esta manera, cuál es la importancia y el papel fundamental de los abuelos para la cohesión y transmisión de los valores inherentes al concepto amplio y actual de Familia. 
el juez se convierte en una figura clave y en el eje fundamental para analizar, caso por caso, de qué forma se pueden adoptar medidas que favorezcan a los más perjudicados $y$, particularmente, a los menores de edad ante situaciones de crisis matrimonial. ${ }^{9}$

La reforma del Código Civil de 1981 supuso un cambio radical respecto a la situación anterior, ya que modificó la regulación del matrimonio que hasta entonces estaba vigente. No obstante, esta norma que nació fruto de las circunstancias políticas e ideológicas que rodearon a la Constitución de 1978, hoy está en constante cambio porque no se adapta a las necesidades sociales. ${ }^{10}$

Por tal motivo, el Consejo de Ministros aprobó el 26 de noviembre de 2004 un novedoso Proyecto de Ley de Divorcio, el cual tiene como propósito adaptar la ley a las necesidades sociales a través de un cambio sustancial en los preceptos que regulan esta materia. De entre las novedades se destacan:

- La eliminación de las causas de divorcio contempladas en el artículo 85 del cc, de manera que es necesario cumplir los requisitos del artículo $81 \mathrm{cC}$ en su nueva redacción. Con ello se consigue dejar vacío el cap. viII del cC.

- Mayor brevedad de los plazos, los cuales pasan a ser de tres meses (salvo en el caso de malos tratos previa denuncia en el que no se requiere el cumplimiento de dicho plazo).

- Se pretende evitar el doble procedimiento.

- Se produce el ejercicio de la custodia compartida ${ }^{11}$ (aunque es necesario revisar caso por caso, ya que esto puede llevar a situaciones difíciles de resolver en razón a los intereses en juego). Artículos 90 y 92 cc.

Asimismo, de esa reforma introducida por el Código Civil español en el 2005, sobresale que se

9. Véase Auto de 30 de julio de 1999. [Juzgado de Primera Instancia N. ${ }^{\circ} 1$ de Calahorra]. Julio 30 de 1999.

10. De este modo lo expone el profesor Riesgo, al admitir específicamente: "La facilidad dada por el divorcio a la hora de rehacer la vida es, quizá, la principal causa de muchos fracasos matrimoniales [...] desde la Ley de 1981 se han dictado por los Tribunales civiles españoles más de 800.000 sentencias de separación matrimonial [...] este aniversario ha sido una fecha silenciada por la inmensa mayoría de los diarios de ámbito nacional [...] hoy estamos esperando una nueva reforma que solucione los problemas que hacen quebrar al concepto de Familia tradicional burguesa del s. XIX" (pp. 54 y ss). Véase Luis Riesgo. Divorcio isolución o problema?: veInte AÑOS DE DIVORCIO, 1981-2001. Comercial. (2001).

11. Así reza en la Exposición de Motivos del citado Proyecto de Ley del Divorcio de 26 de noviembre de 2004: "Se contempla expresamente que los padres puedan acordar en el convenio regulador que el ejercicio se atribuya exclusivamente a uno de ellos, o bien a ambos de forma compartida". permite a personas del mismo sexo unirse legítimamente en un matrimonio produciendo los mismos derechos y obligaciones. De esta forma se extiende, desde entonces, una nueva terminología que incluye otras relaciones frecuentes surgidas de forma paralela al matrimonio, tales como las parejas de hecho, las uniones libres o la convivencia more uxorio. Así comenzaba su "Exposición de Motivos", al afirmar específicamente que la relación y convivencia de pareja basada en el afecto es:

Una expresión genuina de la naturaleza humana y constituye cauce destacado para el desarrollo de la personalidad, que nuestra Constitución establece como uno de los fundamentos del orden político y la paz social. En consonancia con ello, una manifestación señalada de esta relación, como es el matrimonio, viene a ser recogida por la Constitución, en su artículo 32, y considerada, en términos de nuestra Jurisprudencia constitucional, como una institución jurídica de relevancia social que permite realizar la vida en común de la pareja. Esta garantía constitucional del matrimonio tiene como consecuencia que el legislador no podrá desconocer la institución, ni dejar de regularla de conformidad con los valores superiores del ordenamiento jurídico, y con su carácter de derecho de la persona con base en la Constitución. ${ }^{12}$

En suma, la realidad de hoy permite ver cómo se está ante una época de cambios, la cual precisa de la aplicación de las normas legales en atención al caso concreto, y a los intereses que puedan verse afectados en relación con el resultado final decretado por la sentencia que resuelva la situación de crisis matrimonial. Y así, de esta manera, tratar de adaptarse mejor a las nuevas propuestas originadas por el cambio social de estas últimas décadas respecto al concepto tradicional de "familia" y a su importancia en nuestra sociedad actual.

\section{EVOLUCIÓN JURÍDICA DE LOS JUICIOS MATRIMONIALES EN LOS ÚLTIMOS AÑOS}

Desde la aparición del Código Civil español en el siglo XIX, se han dado transformaciones importantes respecto a la regulación del matrimonio, con el fin de adaptar la ley a las demandas sociales. Esto en

12. Reforma al Código Civil español, 2005. Exposición de Motivos. 
razón a las reformas introducidas con la Ley $30 / 1981^{13}$ la Ley $42 / 2003^{14}$ y la Ley $13 / 2005 .^{15}$

Es importante para el desarrollo de este artículo detenerse en la Ley 30 de 1981, ya que esta, aunque data de hace tres décadas, ayuda a determinar las pautas a seguir con los procesos matrimoniales en los que se trate de preservar los intereses de los afectados. Lo anterior a través de unas medidas que garanticen un equilibrio racional a la situación de crisis matrimonial. En concreto, se hace referencia a la adopción de las siguientes pautas:

- Medidas provisionales previas al proceso correspondiente para los casos de nulidad, separación o divorcio.

- Medidas provisionales simultáneas al proceso.

- Procedimiento para la homologación de las sentencias de separación y divorcio, dictadas por tribunales extranjeros. ${ }^{16}$

- Procedimientos para la homologación en España de las resoluciones dictadas por los tribunales eclesiásticos sobre nulidad del matrimonio canónico.

- Procedimiento para la sustanciación de las demandas de separación y divorcio, sin mutuo acuerdo o por causas comprendidas en los apartados 2 y 3 del artículo 73 cC.

- Procedimiento para la sustanciación de las peticiones de separación o divorcio, de común acuerdo, o por uno de ellos con consentimiento del otro. ${ }^{17}$

Como regla general, es posible ver cómo las características inexcusables que se deben dar en todos los juicios matrimoniales en los cuales estén en juego intereses que afecten el normal desarrollo de las relaciones son: a) una acción ejercitable exclusivamente por las partes; b) que el juez posea la iniciativa probatoria en todos los casos; c) las reglas de competencia sean improrrogables; d) no se aplique la confesión como medio de prueba; ${ }^{18}$ e) se respete el derecho a los terceros interesados en la solución que dé el juez al final del proceso; y f) se debe exigir, en todo caso,

\footnotetext{
13. Véase Ley 30/1981, supra, nota 5.

14. Véase Ley $42 / 2003$, supra, nota 8.

15. Véase Ley $13 / 2005$, supra, nota 1.

16. Véase SAS, Baleares, de 31 de marzo 2004; ATs, de 11 de mayo de 2004; SAP, Barcelona, de 20 de mayo de 2004; SAP, Lleida, de 20 de mayo de 2004. (Competencia judicial internacional en relación con el divorcio de cónyuges españoles con residencia en Andorra). 17. Véase Auto de fecha de 30 de julio de 1999, supra, nota 9.

18. Véase Auto de 19 de noviembre de 1999 [Juzgado de Primera Instancia N. ${ }^{\circ} 2$ de Coslada]. Noviembre 19 de 1999; y Auto de 22 de octubre de 1999 [Juzgado de Primera Instancia N. 6 de Orihuela]. Octubre 22 de 1999.
}

la igualdad de las partes, así como garantizarse la posibilidad de la doble instancia.

La práctica de los tribunales civiles a la hora de llevar a cabo estas reglas se ve dificultada por la falta de acuerdo de las partes que se presentan ante estos casos, sobre todo en relación con el régimen económico del matrimonio tras la separación o divorcio, o el ejercicio de la patria potestad compartida respecto a los hijos nacidos en el matrimonio. ${ }^{19}$

\section{JURISPRUDENCIA ACTUAL DE LOS}

\section{TRIBUNALES CIVILES ANTE SITUACIONES DE CRISIS MATRIMONIAL}

A continuación se analizan distintos supuestos que se dan en la práctica, relacionados con la regulación del régimen económico del matrimonio y las cargas, así como con los deberes que tienen determinados parientes con los hijos que se ven afectados por esta situación. Se deben tener en cuenta los cambios sociales y la apertura a nuevas posibilidades que no se contemplaban hace unas décadas, tal como se ha señalando desde el inicio de este artículo.

Particularmente, un ejemplo de esas recientes transformaciones en el ámbito familiar se encuentra en el creciente delito de impago de pensiones alimenticias en supuestos de crisis, recogido en el artículo 227.1 del Código Penal español, pues se presenta como uno de los que más ha aumentado en las estadísticas judiciales. ${ }^{20}$ En concreto, tal como refleja la propia Memoria de la Fiscalía General del Estado del año 2012, este tipo de delito constituye en España el más numeroso de los que tienen por objeto incumplimientos graves de los deberes que se derivan de las relaciones familiares, con un aumento del $12,48 \%$ :

Y ello es debido a la situación económica existente en España, de gran calado en las economías domésticas, en la que el progenitor no custodio (hombre o mujer) deja de contribuir al pago de la pensión de alimentos a su/s hijo/s que por resolución judicial viene obligado. Aunque ante este incumplimiento también se puede acudir a la jurisdicción civil, es la vía penal la que con más frecuencia el perjudicado-acreedor

19. Véase SAP de la Coruña, de 17 de septiembre de 2001. 20. Véase Natalia Junquera. Pensión alimentaria hasta los 31. EL PAís. Octubre 31 de 2014. Disponible en http://politica.elpais.com/ politica/2014/10/30/actualidad/1414708075_972310.html 
se asoma con esperanza de que sus problemas se vean pronto resueltos. ${ }^{21}$

Sobre este particular, cabe recordar que el Código Civil español no especifica una edad máxima para que un hijo siga recibiendo dinero de su progenitor. Si bien es cierto que establece las causas que eximen del pago de esa pensión en su artículo 152, las cuales se señalan textualmente a continuación:

\section{1. ${ }^{\circ}$ Por muerte del alimentista.}

2. ${ }^{\circ}$ Cuando la fortuna del obligado a darlos se hubiere reducido hasta el punto de no poder satisfacerlos sin desatender sus propias necesidades y las de su familia. 3. ${ }^{\circ}$ Cuando el alimentista pueda ejercer un oficio, profesión o industria, o haya adquirido un destino o mejorado de fortuna, de suerte que no le sea necesaria la pensión alimenticia para su subsistencia.

4. ${ }^{\circ}$ Cuando el alimentista, sea o no heredero forzoso, hubiese cometido alguna falta de las que dan lugar a la desheredación.

5. ${ }^{\circ}$ Cuando el alimentista sea descendiente del obligado a dar alimentos, y la necesidad de aquél provenga de mala conducta o de falta de aplicación al trabajo, mientras subsista esta causa. ${ }^{22}$

Desde que empezó la crisis a nivel global, son frecuentes las sentencias del Tribunal Supremo en las que se recoge la obligación del progenitor de seguir pagando una pensión a sus hijos mayores de edad cuando la situación de dependencia no es imputable al hijo, es decir, cuando no encuentra trabajo en razón a la crisis financiera que ha generado un gran número de desempleados. De hecho, una sts del 12 de julio de 2014 obligó a un padre a volver a pagar a su hija una pensión alimenticia ya que, pese a tener 27 años y una titulación profesional, carecía de trabajo e ingresos suficientes para ser independiente. No obstante, con carácter excepcional y novedoso llama la atención la ya mencionada STs del 2 de marzo del $2015,{ }^{23}$ pues en ella el tribunal exime de dicha pensión alimenticia con base en los siguientes argumentos, extraídos literalmente de la sentencia:

Aunque esta obligación de prestar alimentos a los hijos se constituye en un deber inexcusable, no es el mismo tan absoluto que obligue a su mantenimiento cuando consta acreditado en autos que el progenitor

21. Véase Ministerio de Justicia. Memoria de la Fiscalía General DEL Estado DEL AÑo 2012. Centro de Estudios Jurídicos. (2012).

22. Código Civil de España [CCE]. Artículo 152. 1889. (España).

23. Véase Tribunal Supremo, supra, nota 2. a quien se reclaman carece de ingresos o estos son tan reducidos que no alcanzan a cubrir siquiera sus propias necesidades, que vienen siendo atendidas por sus familiares y/o amigos, pues en ese caso esa carencia se convierte evidentemente en una causa de fuerza mayor que impide incluso la fijación del denominado mínimo vital, al convertirse en una prestación imposible [...] Ante una situación de dificultad económica habrá de examinarse el caso concreto [...] Ocurre así en este caso - carácter muy excepcional- en atención a los datos que valora la sentencia recurrida. ${ }^{24}$

\section{A. El cambio en el concepto de "familia" en las últimas décadas}

Una de las reformas que más consecuencias tiene en la práctica se deriva de la ampliación del concepto de "familia". Se pasa de un concepto de familia nuclear propio del siglo xIX, en el cual - gracias a la Revolución francesa- únicamente tenían cabida los cónyuges y los hijos habidos en el matrimonio, a una noción más abierta y adaptada a las necesidades sociales en la que se consiente - por parte de la doctrina ${ }^{25} \mathrm{y}$ de la sociedad- la aparición de nuevos vínculos. Entre estos, se destacan las parejas de hecho formadas por dos personas que conviven sin haberse casado por cualquiera de las dos formas previstas en el Cc (civil o religiosa), parejas de homosexuales, familias monoparentales, o la posibilidad de que los abuelos obtengan el ejercicio de la patria potestad en los casos previstos.

En concreto, se encuentra cómo el Tribunal Constitucional reconoció en la Sentencia del 16 de octubre del $2000^{26}$ una indemnización por la muerte en accidente de tráfico de un individuo, el cual, casado y no separado, convivía maritalmente con otra mujer. El tribunal optó por la distribución entre la esposa y la compañera sentimental con base en el principio de prorrata temporis, el cual se aplica en función de la duración de ambas relaciones (en el caso planteado se trataba de 25 años con la esposa y 18 de convivencia con la compañera sentimental).

En relación con la reforma llevada a cabo por la Ley $42 / 2003,{ }^{27}$ sobre las posibilidades de que los abuelos protejan a sus nietos si existe previo consentimiento,

\footnotetext{
24. Id.

25. De esta se destaca, especialmente, la seguida por Valpuesta Véase Rosario Fernández Valpuesta. La encrucijada de la Familia: Entre la realidad social y el Derecho. Boletín Mexicano DE Derecho Comparado 9. 2004. Págs. 89-120

26. Tribunal Constitucional. Sentencia 241/200o. (Octubre 16 de 2000).

27. Véase Ley $42 / 2003$, supra, nota 8
} 
la Sentencia de la AP de Zaragoza del 19 de febrero de $2001^{28}$ confiere la tutela a la hermana de la fallecida en un accidente de tráfico, negándosela a los abuelos paternos (se observa, por ende, la preferencia de que sea una mujer joven familia de la madre, ante los abuelos por parte del padre fallecido tres años antes).

Sin embargo, en la Sentencia del 2 de octubre de 2003, el Ts enjuicia un caso en el que se priva del ejercicio de la patria potestad al demandado sobre sus hijos menores por haber matado a su esposa. En el supuesto, las medidas que en primera instancia tomó el juez fueron, entre otras, la declaración de sometimiento de los menores a un régimen de tutela provisional a los abuelos maternos, y la condena al demandado al abono de una pensión por razón de alimentos. Lo curioso es que se observa cómo en las últimas décadas el concepto nuclear de familia se ha ido ampliando y, ahora, gracias a la Ley $42 / 2003,{ }^{29}$ se da la atribución a los abuelos de la función tuitiva y de guarda respecto a sus nietos en caso de dejación por los padres de las obligaciones derivadas del ejercicio de la patria potestad. La privación de la patria potestad viene expresada por el Ts en los siguientes términos:

Fundamento N. ${ }^{\circ} 1:$ [...] la privación de la patria potestad con pleno y sólido asiento en el artículo 170 viene avalada por haber cometido el delito de parricidio [...] es por tanto necesario el consentimiento de los abuelos, para que sean estos los que de forma provisional, se encarguen de la guardia y custodia de los menores [...] para tratar de no lesionar intereses que se pudieran derivar de la tramitación del proceso [...].

En la sTC de enero de $2001,{ }^{30}$ por su lado, se plantea un recurso de amparo frente a la sentencia de apelación que modifica la guarda y custodia del hijo habido en el matrimonio, acordándola compartida por meses alternos sin haber sido planteada por los litigantes. El Tribunal Constitucional desestima el amparo al considerar que no incurre en incongruencia lesiva del $24 \mathrm{CE}$, ya que la decisión judicial se toma en interés del menor. El problema viene dado respecto a la aplicación, tal como señala el Proyecto de Reforma de Ley de Divorcio de 2004, de los artículos 90 y $92 \mathrm{cc}$, a fin de salvaguardar el interés del menor asegurando el cumplimiento de las cargas impuestas por el juez a sus progenitores, ya que al no existir convivencia conyugal se complica el ejercicio de la custodia compartida.

28. Cf. Ap de Zaragoza. Sentencia. (Febrero 19 de 2001).

29. Véase Ley $42 / 2003$, supra, nota 8.

30. Tribunal Constitucional. Sentencia 4/2001. (Enero 15 del 2001).
Otro supuesto se encuentra en la Sentencia del 22 de noviembre del $2000,{ }^{31}$ en la cual el ts reconoce la paternidad del recurrente respecto a dos hijos gemelos habidos con la demandante. La negativa injustificada a someterse a las pruebas biológicas de la paternidad necesita ser valorada con otras indiciarias, a fin de llevar a cabo la declaración de paternidad.

\section{B. Limitación temporal ab initio de la pensión compensatoria}

Uno de los problemas actuales a la hora de regular la situación económica de los cónyuges tras la crisis se deriva de la posibilidad que ofrece el artículo $97 \mathrm{del}$ $\mathrm{CC}^{32}$ en el sentido de que todo aquel descompensado pueda recibir una ayuda temporal, previo acuerdo del juez y con petición de la parte afectada.

La pensión compensatoria trata de resarcir el desequilibrio económico a través del principio de solidaridad entre los dos. Es numerosa la jurisprudencia acerca de la limitación temporal ab initio de la pensión compensatoria, pero cabe destacar la SAP de Córdoba de 25 de marzo de 1999, en la que se afirma la doctrina reiterada:

La pensión compensatoria no presupone, como los alimentos entre cónyuges, una situación de necesidad en el acreedor, sino una constatación de un efectivo desequilibrio económico en perjuicio suyo, lleve o no aparejada aquella situación de necesidad..$^{33}$

La doctrina jurisprudencial ha venido planteando como premisa para el establecimiento de una pensión limitada en el tiempo la previsibilidad o no de su extinción. Esto para los casos en los que uno de los cónyuges haya de afrontar el resto de sus días ciertas secuelas, o soportar cargas derivadas de la convivencia matrimonial que, lejos de desaparecer, están llamadas a permanecer indefinidamente. La temporalidad de la pensión no puede ni siquiera plantearse, pues se asiste a lo que bien pudiera denominarse un desequilibrio perpetuo, caso al que alude la sAP de Cádiz de 14 marzo de 2000. ${ }^{34}$

No obstante, se observa en la jurisprudencia reciente que, como regla general, se procede a la limitación temporal del derecho compensatorio cuando en el momento de la separación o divorcio, aunque exista una desproporción en perjuicio de uno de los esposos, el afectado es una persona joven que

\footnotetext{
31. Tribunal Supremo. Sentencia 1084/200o. (Noviembre 22 de 2000).

32. Código Civil de España [CCE]. Artículo 97. 1889. (España).

33. Véase Audiencia Provincial de Córdoba. (Marzo 25 de 1999).

34. Véase Audiencia Provincial de Cádiz. (Marzo 14 de 2000).
} 
trabaja o la cual, por su titulación académica, tiene posibilidades de hacerlo y no existen excesivas cargas familiares. Lo decisivo no es la posibilidad actual real de contar con una fuente de ingresos propia, sino las condiciones personales del cónyuge acreedor que le permitan buscarla y conseguirla. ${ }^{35}$

En la sentencia del Ts del 17 de junio del 2003, ${ }^{36}$ se analiza un caso en el que se condena al acusado por delito de abandono de familia a causa del impago de pensiones $\mathrm{y}$, además, por delito de alzamiento de bienes. El ts toma como referencia el artículo $97 \mathrm{del}$ CC, ${ }^{37}$ y agrava su situación en razón a la transmisión del acusado a su compañera sentimental de la mitad indivisa de la finca registral impidiendo con su actuación la ejecución de sus créditos. La sentencia de instancia le condena como autor del delito de abandono de familia, y por vía civil deberá abonar el pago de una cantidad que compense el impago de las prestaciones económicas impuestas a favor y en interés de los menores protegidos durante el periodo debido.

\section{Violencia doméstica: El requisito de la denuncia previa}

Otro problema que se encuentra en la realidad es el derivado de aquellas situaciones de violencia doméstica, en las que se entremezcla el Derecho civil y el Derecho penal. En concreto, hasta la aprobación de la Ley $13 / 2005,{ }^{38}$ por la que se modificaba el Código Civil en materia de derecho a contraer matrimonio, el proyecto ya establecía en su artículo 81 que, para la separación o el divorcio en casos en los que existan maltratos, no será preciso cumplir el plazo fijado de tres meses si existe denuncia previa que constate los hechos declarados. Se trata así de abreviar los plazos y buscar lesionar lo menos posible a los menores o al cónyuge víctima del maltrato.

A continuación se analizan distintos casos en los que tras la interposición de denuncia por malos tratos, y/o estando la víctima refugiada en una casa de acogida, se adoptan distintas medidas en interés de los menores afectados dependiendo de las circunstancias del caso.

1. Autos en los que se deniega la tramitación de medidas previas de separación porque la solicitud carece de urgencia

35. Cf. Audiencia Provincial de Cádiz. (Julio 13 de 1999).

36. Tribunal Supremo. Sentencia. (Junio 17 de 2003).

37. Código Civil de España [CCE], supra, nota 32.

38. Véase Ley 13/2005, supra, nota 1.
El requisito de urgencia que venía establecido en el apartado 2 del artículo 1881 de la Ley de Enjuiciamiento Civil (LEC) ${ }^{39}$ desapareció con la Ley $34 / 84^{40}$ de modificación de la antigua LEC. No obstante, ya desde la Ley $30 / 81^{41}$ resultaba inaplicable el requisito normativo de urgencia para la adopción de medidas previas de separación, nulidad y divorcio, dado que su "Disposición Adicional 4" remite a los trámites de los arts. 1884-1885 LEC, sin referencia al artículo 1881 LEC. Sin embargo, la admisión a trámite de las medidas previas de separación sigue condicionando este presupuesto. El auto de fecha de 22 de octubre de 1999 establece en sus "Razonamientos Jurídicos" cómo "la presente solicitud ha de desestimarse [...] porque carece de la urgencia que la adopción de las medidas provisionalísimas requieren". ${ }^{42}$

2. Autos en los que se acuerdan medidas previas de separación, pero no se adoptan ningún tipo de medidas especiales, pese a constar una situación de violencia familiar

En los siguientes autos se busca comprobar cómo algunas veces no se tiene en cuenta la situación de violencia familiar en las medidas que se han adoptado.

Los hijos son víctimas de la violencia - ya sea de forma directa o indirecta- al presenciar cómo su progenitor golpea a su madre de forma injustificada. Los hijos no son insensibles o indiferentes, sino que sufren al ver una situación de anormalidad que muchas veces se refleja en su carácter y en sus relaciones con los demás, razón por la cual se suele adoptar la suspensión del régimen de visitas de los menores respecto al progenitor maltratador. El auto de fecha 19 de noviembre de 1999 establece en su "Razonamiento Jurídico Segundo" que:

Siendo preciso valorar la necesidad de urgencia del caso, con el fin de evitar que se adopten medidas jurídicas [...] no injustificadas [...] constando que la situación es difícil, y que la menor, en su exploración, manifiesta temor a que su padre agreda a su madre, parece justificado adoptar medidas provisionalísimas:

1.- La separación provisional de los cónyuges [...]

39. Real Decreto de 3 de febrero de 1881. [Ministerio de Gracia y Justicia]. Promulgación de la Ley de Enjuiciamiento Civil. Febrero 5 de 1881 . Gaceta N. ${ }^{\circ} 36$.

40. Ley 34/84. De reforma urgente de la Ley de Enjuiciamiento Civil. Agosto 7 de 1984. воE N. ${ }^{\circ} 188$.

41. Ley 30/81, supra, nota 5.

42. Auto de 5 de agosto (Getafe), en relación con el Auto del 26 de abril de 1996 (Madrid) 
2.- La guarda y custodia de los hijos se atribuye a la madre [...]

3.- La atribución del uso del domicilio y disfrute de la vivienda familiar, se atribuye a la esposa [...]

4.- En concepto de contribución a los alimentos para los hijos, el esposo abonará, por meses anticipados [...] la cantidad de treinta mil pesetas mensuales. ${ }^{43}$

El auto de fecha 30 de julio de 1999 dispone en su "Razonamiento Jurídico Segundo" que:

Existe una situación de convivencia gravemente deteriorada y agravada por el hecho de que la esposa ha abandonado el domicilio conyugal ante el temor de que la golpee su marido [...] dejándole a éste a su hijo de 20 meses [...] se decreta la separación provisional [...] se revocan los consentimientos y poderes que los cónyuges se hubieran otorgado [...] y la posibilidad de vincular bienes de un cónyuge a otro, cesando la presunción de convivencia conyugal [...] la guardia y custodia del menor se adjudica a la madre, pero el padre tendrá derecho a visita [...] y abonará en concepto de alimentos la cantidad de 30.000 ptas mensuales. ${ }^{44}$

\section{Autos en los que se adoptan medidas} provisionalísimas de separación otorgando la guarda y custodia de los hijos al progenitor maltratador

Las medidas previas dada la inmediación con que deben adoptarse, deberían ser un medio efectivo para el cese de la violencia. Sin embargo, en determinadas circunstancias se niega la solicitud de medidas previas de separación, amparándose los jueces en la inexistencia de urgencia ya que no existe convivencia.

Sólo atendiendo al tiempo que ha de transcurrir desde que se solicita abogado y procurador de oficio, hasta que se acuerdan medidas coetáneas de separación, es comprensible la precariedad en que pueden hallarse las mujeres y los hijos que quieren que cese la violencia que padecen. Así, en el auto de medidas provisionalísimas, de fecha de 23 de agosto de 2000 , se razona lo siguiente:

En cuanto a la atribución de la guarda y custodia [...] de conformidad con lo dispuesto en el artículo 159 CC [...] ambos poseen ingresos económicos [...] no constatando la actitud agresiva del esposo [...] la guarda

43. Auto de 19 de noviembre de 1999. [Juzgado de Primera Instancia N. ${ }^{\circ} 2$ de Coslada]. Noviembre 19 de 1999.

44. Auto de 30 de julio de 1999. [Juzgado de Primera Instancia N. 1 de Calahorra]. Julio 30 de 1999. recaerá para el progenitor por tener mayor solvencia económica [...] en interés del menor. ${ }^{45}$

Del análisis realizado se puede deducir que, salvo contadas excepciones, los tribunales civiles tampoco dan respuesta a la violencia familiar. La inseguridad jurídica, ${ }^{46}$ contraria a nuestro Estado de Derecho desde la Constitución Española (CE) de 1978, es la nota predominante en estos procesos. Si bien la mujer es la principal víctima en los últimos años de la violencia doméstica, no encuentra protección ni en el Derecho penal ni en el civil, de manera que se ven desprotegidos los derechos en relación con sus hijos menores nacidos en el matrimonio o en la relación afectiva existente hasta el momento.

\section{Competencia judicial internacional ante nulidad, separación o divorcio}

A propósito del análisis de la actuación de los tribunales internacionales ante situaciones de separación o divorcio, se han de ver las modificaciones previstas por el artículo 3 de la Ley Orgánica (LO) 11/2003, la cual modifica los artículos 9.2 y 107 cC y señala en el número dos de este último artículo (conforme a su nueva redacción):

En todo caso, se aplicará la Ley española a la nulidad, separación o divorcio cuando uno de los cónyuges sea español o resida habitualmente en España:

a. Si no resulta aplicable ninguna de las Leyes mencionadas (nacionalidad común, residencia común, etc.).

b. Si en la demanda presentada ante el Tribunal español, la separación o el divorcio se pide por ambos cónyuges o por uno con el consentimiento del otro.

c. Si las Leyes indicadas en el párrafo primero de este apartado no reconocieran la separación o el divorcio, o lo hicieran de forma discriminatoria, o contraria al orden público. ${ }^{47}$

En la práctica, la aplicación de esta Lo publicada en el Boletín Oficial del Estado (BОЕ) resulta decisiva para resolver las cuestiones referidas a separaciones matrimoniales, divorcio, competencia judicial y ley aplicable al caso concreto.

Desde el Plan de Lucha presentado por el Gobierno el 12 de septiembre de 2002, se ha fortalecido la seguridad ciudadana, se ha combatido la

45. Auto de medidas provisionalísimas. Agosto 23 de 2000.

46. Tribunal Supremo. Sentencia. (Mayo 26 de 2000).

47. Véase Ley Orgánica 11/2003. De medidas concretas en materia de seguridad ciudadana, violencia doméstica e integración social de los extranjeros. Septiembre 29 de 2003. воE N. ${ }^{\circ} 234$. 
violencia doméstica y se ha tratado de favorecer la integración social de los extranjeros, gracias a la adecuación de las instituciones civiles a las nuevas culturas que conviven en nuestro país.

Con la reforma del CC de 2003, se ha posibilitado que en el caso de mujeres de religión musulmana que soliciten el divorcio se aplicará la ley española cuando uno de los cónyuges sea español o residente en España, con preferencia a la ley que fuera aplicable si esta última no reconociera la separación o el divorcio, o lo hiciera de forma discriminatoria o contraria al orden público (tal como prohíbe la modificación incorporada por la LO del 29 de septiembre de $2003^{48}$ respecto al artículo $107.2 \mathrm{CC}$ ).

Un ejemplo de cuál es la competencia y la norma aplicable en estos casos lo provee la sAp de Cuenca del 26 de febrero de 2004, en la que se plantea un caso de separación matrimonial de cónyuges ecuatorianos en relación con lo dispuesto por el nuevo artículo 107 cC y la aplicación de la ley española. En su "Fundamento Primero" se establece cómo "ambos cónyuges ostentan la nacionalidad común ecuatoriana [...] a tenor del artículo 3 de la Lo de 29 de Septiembre de 2003 [...] la ley aplicable a la separación ha de ser la Ley española". ${ }^{49}$

La práctica demuestra cómo cada vez se hace más difícil aclarar la normativa aplicable ante situaciones de crisis matrimonial y la conciliación entre culturas distintas en España, por lo que se habrá de entrar al caso concreto. ${ }^{50}$

\section{AnteCedentes DE LA LEY DEL DIVORCIO: CAMBIOS EN LA REGULACIÓN}

Como se ha visto hasta el momento en el desarrollo de esta exposición, son muchos los cambios que en el Derecho de familia se están produciendo en las últimas décadas a causa de la necesidad de adaptar las necesidades sociales a la realidad y dar a estas una respuesta coherente.

Dehecho, a continuación se analiza el Proyecto de Ley de Divorcio hasta que se aprobó definitivamente la Ley $13 / 2005,{ }^{51}$ para luego hacer una referencia a la

\footnotetext{
48. Id.

49. Juzgado de Primera Instancia N..$^{\circ} 1$ de Cuenca. Sentencia Audiencia Provincial de Cuenca 43/2004. (M. P. Muñoz Hernández, Leopoldo Puente Segura; Febrero 26 de 2004).

50. Audiencia Provincial de Lleida. Sentencia de 20 de mayo de 2004; Audiencia Provincial de Málaga. Sentencia de 31 de marzo de 2004.

51. Véase Ley 13/2005, supra, nota 1.
}

modificación del CC por la Ley $42 / 2003,{ }^{52}$ a propósito de las relaciones familiares de los abuelos respecto a sus nietos, cuando estos se quedan en una situación de desamparo motivada por una crisis matrimonial.

En efecto, el Consejo de Ministros aprobó el 26 de noviembre de 2004 un novedoso Proyecto de Ley de Divorcio que pretendía adaptarse a las necesidades sociales cambiantes en materia de familia, a través de un cambio sustancial en los preceptos que regulan esta materia. En concreto, se trata de las siguientes modificaciones:

- Eliminación de las causas de divorcio contempladas en el artículo 85 del CC, de manera que sea necesario cumplir los requisitos del artículo $81 \mathrm{cC}$ en su nueva redacción. Con ello se consigue dejar vacío el cap. viII del cC.

- Brevedad de los plazos, los cuales pasan a ser de tres meses, salvo en el caso de malos tratos previa denuncia, en el que no se requiere el cumplimiento de dicho plazo.

- Evitar el doble procedimiento.

- Disolución del matrimonio por mutuo acuerdo, sin hacer falta otro requisito que no sea la voluntad de los cónyuges de poner fin a la situación de crisis matrimonial.

- Ejercicio de la custodia compartida ${ }^{53}$ (aunque es necesario revisar caso por caso, ya que esto puede llevar a situaciones difíciles). Artículos 90 y 92 cc.

- Artículos 82 y 87 cc quedan también sin contenido.

- Artículo 97 CC alusivo al régimen económico, tras la separación o divorcio.

De esta forma, la eliminación de las causas, la posibilidad del acceso directo al divorcio sin separación previa y la ampliación de las formas de pago de las pensiones, así como la regulación judicial de la custodia compartida con plenas garantías para los derechos del menor cuando haya acuerdo entre los padres (y, en caso contrario, a partir de la intervención de un juez), son las principales novedades de la reforma.

Respecto a la custodia compartida, se ha dado a conocer en diversos medios de comunicación cómo en el texto propuesto para el próximo Consejo de Ministros se recoge la posibilidad de que los jueces puedan otorgar la custodia compartida de los

\footnotetext{
52. Véase Ley 42/2003, supra, nota 8.

53. Particularmente, en la Exposición de Motivos del mencionado Proyecto de Ley se señala literalmente que: "Se contempla expresamente que los padres puedan acordar en el convenio regulador que el ejercicio se atribuya exclusivamente a uno de ellos, o bien a ambos de forma compartida”.
} 
menores siempre que se cumplan dos requisitos: por un lado, que no exista situación de malos tratos y, por el otro, que no haya un conflicto entre la pareja que perjudique al hijo. En todo caso, el magistrado siempre debe atender al informe que elabore el fiscal $y$ actuar en beneficio del menor.

La custodia compartida ha supuesto igualmente uno de los apartados más reivindicados por las asociaciones de mujeres que solicitaron mantener la potestad del juez para decidir sobre ella, mediante una serie de trabas que, en la práctica, no permitirían que dicha custodia se lleve a cabo.

Explícitamente la concesión de la custodia de los hijos a ambos cónyuges también se recoge en el anterior texto aprobado por el Gobierno, al señalar que si el convenio regulador entre las partes "propone compartir la custodia o el juez considera que esto es lo mejor para el menor, se admitirá que las funciones puedan ser compartidas entre ambos cónyuges"; y añade además: "en cualquier caso, la filosofía de la norma es procurar no separar a los hermanos".

En la "Exposición de Motivos" de la nueva ley, se destaca su objetivo primordial de extender la libertad de los ciudadanos, concibiéndose el derecho al divorcio como una extensión del propio derecho al matrimonio previsto en el artículo 32 de la CE. Como se explica textualmente en la ley en vigor de 1981:

Aún podían advertirse rasgos del antiguo modelo de separación-sanción. El divorcio se concebía como el último recurso al que pudieran acogerse los cónyuges y sólo cuando era evidente que, tras un dilatado período de separación, su reconciliación ya no era factible [...] En ningún caso, el matrimonio podía disolverse como consecuencia de un acuerdo en tal sentido de los consortes. ${ }^{54}$

Las carencias y disfunciones de este texto vigente durante casi un cuarto de siglo sólo sirven de modelo en los casos de separación o divorcio que, antes de resolver la situación de crisis matrimonial, han terminado agravándola, o en los que su duración ha llegado a ser superior a la de la propia convivencia conyugal. Por eso, conforme a los nuevos parámetros sociales, esta reforma pretende que "la libertad, como valor superior de nuestro ordenamiento jurídico, tenga su más adecuado reflejo en el matrimonio". Se trata ahora de reconocer mayor trascendencia a la voluntad de la persona cuando ya no desea seguir vinculado con su cónyuge. Así,
El ejercicio de su derecho a no continuar casado no puede hacerse depender de la demostración de concurrencia de causa alguna, pues la causa determinante no es más que el fin de esa voluntad expresada en su solicitud, ni, desde luego, de una previa e ineludible situación de separación.

Como consecuencia de esto, se pretende dar una mayor responsabilidad a los padres en el desarrollo de la vida de sus hijos menores, dentro de una sociedad más igualitaria en el reparto de las cargas familiares.

En ocasiones y en atención a las circunstancias del caso, no es posible el ejercicio de la patria potestad por ninguno de los dos progenitores, ${ }^{55}$ por lo que con carácter subsidiario y de forma expresa se acepta, en razón a la modificación del cc realizada por la Ley $42 / 03,{ }^{56}$ la posibilidad de que sean los abuelos los que voluntariamente acepten la guarda y custodia de sus nietos.

Una vez más, la voluntad del menor prima sobre otras circunstancias y se amplía el concepto tradicional de familia a la figura del abuelo. En concreto, la "Exposición de Motivos" dispone que,

Los abuelos desempeñan un papel fundamental de cohesión y transmisión de valores en la Familia, que es el agente de solidaridad por excelencia de la sociedad civil [...] el legislador no puede olvidar, que el ámbito familiar no se circunscribe únicamente a las relaciones paternofiliales [...] se refuerza el régimen de relaciones de los abuelos y los nietos, tanto en la ruptura familiar, como en el caso de simple dejación de obligaciones por parte de los progenitores [...] cumpliendo una función relevante.

En relación con las modificaciones en los preceptos, cabe destacar las siguientes:

- El artículo 94 CC queda modificado con el fin de recoger la posibilidad de pronunciamiento judicial sobre el régimen de visitas y comunicación del menor con sus abuelos.

- El artículo 103 CC, en conformidad con lo dispuesto en el artículo 90 CC, prevé la decisión jurisdiccional (cuando falte el acuerdo entre los cónyuges) de encomendar a los abuelos la tutela de los hijos de forma excepcional, pero antepuesta a la posibilidad de otorgar este cuidado a otros parientes, otras personas o instituciones. Se aplica el artículo 160 CC no sólo a las rupturas matrimoniales, sino que lo amplía a actuaciones de desinterés de los progenitores o a la ausencia de uno de ellos. 
- El artículo $161 \mathrm{CC}$, por su parte, recoge de forma explícita el régimen de visitas y relaciones entre los abuelos y los nietos sometidos a acogimiento.

\section{Conclusiones}

La reciente sTs del 2 de marzo de $2015^{57}$ por la que se añaden excepciones a la doctrina generalizada de la sala, la cual venía imponiendo el cumplimiento del denominado "mínimo vital" en los supuestos en los que existiesen dificultades económicas para el pago de las pensiones de los hijos ante una separación o divorcio, lleva a investigar cuál ha sido la evolución jurídica de la actuación de los tribunales civiles frente a situaciones de crisis matrimonial y crisis económica, en el marco de los nuevos modelos de familia.

Sobre este particular cabe recordar que, según la jurisprudencia de las Audiencias Provinciales españolas, ese mínimo vital (que oscila entre unos 150 a 200 euros, aproximadamente), constituye una prestación alimenticia obligatoria a favor de los menores, ${ }^{58}$ la cual, salvo enfermedad, falta de capacidad o de aptitud para acceder al mercado de trabajo, se ha venido estableciendo hasta marzo del 2015 como obligatoria aunque el progenitor no obtuviera ingreso alguno.

Así, el objetivo de esta investigación es tratar de delimitar detalladamente cuál es la perspectiva actual en relación con los procesos de nulidad, separación y divorcio, a fin de adaptarlos a las nuevas necesidades sociales y a los nuevos modelos familiares a los que en los últimos tiempos es necesario hacer frente. Todo esto desde una visión comparada y a un nivel global respecto a otros países.

La regulación contenida en nuestro CC español acerca de las situaciones de crisis matrimonial, resulta insuficiente en el propósito de atender las demandas sociales y proteger los intereses de quienes se ven más desamparados por estas situaciones, esto es, los hijos menores. La reforma del cC, dada por la Ley de 1982, supuso un gran avance a la hora de delimitar cuáles eran los requisitos necesarios para que el juez, en el caso concreto, decretara la separación o el divorcio. Sin embargo, se ha comprobado cómo

57. Véase Tribunal Supremo, supra, nota 2.

58. Véase vVAA. El Ts reitera que la obligación de satisfacer un "mínimo vital" al menor solo puede suspenderse en supuestos muy excepcionales. Noticias Jurídicas. Marzo 7 de 2015. Disponible en http://noticias.juridicas.com/juris/594-el-ts-reitera-que-la-obligacion-de-satisfacer-un-minimo-vital-al-menor-solo-puede-suspenderse-en-supuestos-muy-excepcionales.html más de dos décadas después esto es insuficiente si se busca responder a las peticiones de nuestra sociedad. La actuación del juez parece decisiva a fin de conciliar intereses y salvaguardar las situaciones de crisis matrimonial a través de la adopción de medidas previas, provisionales o definitivas que protejan a los afectados en estos casos. ${ }^{59}$ La LEC del año $2000^{60}$ es en este sentido muy innovadora, ya que mejora los procedimientos y los ajusta a las necesidades de cada caso y al interés de los más desprotegidos y afectados por la situación. ${ }^{61}$

En cuanto a la Ley 13/2005, por la que se modifica el Código Civil en materia de derecho a contraer matrimonio, en relación con la modificación prevista por la Ley $41 / 2003,{ }^{62}$ respecto a los abuelos es posible argüir que se aprecia claramente cómo el concepto tradicional de familia se amplía a fin de reconocer la autonomía de las partes a la hora de decidir si continúan o no con el matrimonio. Se trata pues de extender el derecho al matrimonio reconocido en el artículo 32 CE al derecho al divorcio, pero abreviando los plazos, de manera que se evite el doble procedimiento de separación para obtener el divorcio y añadiendo la posibilidad de custodia compartida de los padres.

Una investigación que aborde la consideración y los efectos jurídicos de la gran variedad de uniones extrafamiliares surgidas en Roma puede ayudar a comprender los problemas actuales, derivados tras la reforma introducida por nuestro Código Civil español en el 2005. Esto en razón a que el legislador permitió a personas del mismo sexo unirse en un matrimonio legal, lo cual produce los mismos derechos y obligaciones de la unión considerada tradicionalmente como "matrimonio". Extendiéndose, desde entonces, una nueva terminología que incluye otras relaciones

59. Véase la explicación realizada acerca de la adopción de las medidas reconocidas en la Ley 30 de 1981, y las novedades de la Ley 1/2000 de Enjuiciamiento Civil.

60. Véase Ley $1 / 2000$, supra, nota 6.

61. Véase Auto de fecha 19 de noviembre de 1999. Allí, en su "Razonamiento Jurídico Segundo", establece: "Siendo preciso valorar la necesidad de urgencia del caso, con el fin de evitar que se adopten medidas jurídicas [...] no injustificadas [...] constando que la situación es difícil, y que la menor, en su exploración, manifiesta temor a que su padre agreda a su madre, parece justificado adoptar medidas provisionalísimas: 1.- La separación provisional de los cónyuges [...]. 2. La guarda y custodia de los hijos se atribuye a la madre [...]. 3.- La atribución del uso del domicilio y disfrute de la vivienda familiar, se atribuye a la esposa [...]. 4.- En concepto de contribución a los alimentos para los hijos, el esposo abonará, por meses anticipados [...] la cantidad de treinta mil pesetas mensuales".

62. Véase Ley 41/2003. De protección patrimonial de las personas con discapacidad y de modificación del Código Civil, de la Ley de Enjuiciamiento Civil y de la Normativa Tributaria con esta finalidad. Noviembre 18 de 2003. вов N. ${ }^{\circ} 277$. 
surgidas de forma paralela al matrimonio, tales como las tan frecuentes hoy parejas de hecho, parejas no casadas, uniones extramatrimoniales, uniones de hecho, convivencia more uxorio o uniones libres. ${ }^{63}$

Con todo esto se pretende, por ende, que la institución del matrimonio sea cada vez más un medio para unir a dos personas que voluntariamente han pretendido ejercer su ius conubii. Ampliándose por ello la posibilidad de tutela por los abuelos ${ }^{64}$ como vía para la protección del menor, tal como se desprende de la redacción de la "Exposición de Motivos" de la ley, en la que se afirma:

Los abuelos desempeñan un papel fundamental de cohesión y transmisión de valores en la Familia, que es el agente de solidaridad por excelencia de la sociedad civil [...] el legislador no puede olvidar, que el ámbito familiar no se circunscribe únicamente a las relaciones paternofiliales [...] se refuerza el régimen de relaciones de los abuelos y los nietos, tanto en la ruptura familiar, como en el caso de simple dejación de obligaciones por parte de los progenitores [...] cumpliendo una función relevante.

La práctica demuestra, en suma, lo difícil que es llevar a cabo las medidas acordadas por el juez en interés del menor, de manera que se espera de estas reformas la instrumentación jurídica necesaria para solucionar los problemas de aquellas familias que se encuentran en situación de crisis matrimonial, la cual es motivada por distintas circunstancias, entre las que se destaca la violencia doméstica por ser un grave problema que, hoy por hoy, destruye numerosos matrimonios. ${ }^{65}$

63. En relación con el Derecho de familia y las distintas formas de convivencia entre dos personas de diferente sexo o incluso del mismo, véase Patricia Panero Oria. El concubinato romano como antecedente de las actuales parejas de hecho. Revista Internacional de Derecho Romano 5. 2010. Págs. 92-125. 64. Véase Sentencia de 2 de octubre de 2003, "Fundamento N. ${ }^{\circ}$ ": "La privación de la patria potestad con pleno y sólido asiento en el artículo 170 viene avalada por haber cometido el delito de parricidio [...] es por tanto necesario el consentimiento de los abuelos, para que sean estos los que de forma provisional, se encarguen de la guardia y custodia de los menores [...] para tratar de no lesionar intereses que se pudieran derivar de la tramitación del proceso". 65. Véase el auto de fecha 30 de julio de 1999, el cual dispone en su "Razonamiento Jurídico Segundo": "Existe una situación de convivencia gravemente deteriorada y agravada por el hecho de que la esposa ha abandonado el domicilio conyugal ante el temor de que la golpee su marido [...] dejándole a éste a su hijo de 20 meses [...] se decreta la separación provisional [...] se revocan los consentimientos y poderes que los cónyuges se hubieran otorgado [...] y la posibilidad de vincular bienes de un cónyuge a otro, cesando la presunción de convivencia conyugal [...] la guardia y custodia del

\section{REFERENCIAS}

Antonio Contreras. El delito de impago de pensiones alimenticias. Breve guía jurídica, artículos doctrinales: Penal (2014). Noticias Jurídicas. Julio 7 de 2014. Disponible en http://noticias. juridicas.com/ conocimiento/ articulos- doctrinales/4895-el-delito-de-impago-de-pensiones-alimenticias-breve-guia-juridica/

Audiencia Provincial de Málaga. Sentencia de 31 de marzo de 2004.

Audiencia Provincial de Lleida. Sentencia de 20 de mayo de 2004.

Auto de 5 de agosto (Getafe), en relación con el Auto de 26 de abril de 1996 (Madrid).

Auto de 30 de julio de 1999 [Juzgado de Primera Instancia N. ${ }^{\circ} 1$ de Calahorra]. Julio 30 de 1999.

Auto de 22 de octubre de 1999 [Juzgado de Primera Instancia N. ${ }^{\circ} 6$ de Orihuela]. Octubre 22 de 1999.

Auto de 19 de noviembre de 1999 [Juzgado de Primera Instancia N. ${ }^{\circ} 2$ de Coslada]. Noviembre 19 de 1999.

Código Civil de España [CCE]. (España).

Juzgado de Primera Instancia N. ${ }^{\circ} 1$ de Cuenca. Sentencia Audiencia Provincial de Cuenca 43/2004. (M. P. Muñoz Hernández, Leopoldo Puente Segura; Febrero 26 de 2004). Disponible en http://portaljuridico. lexnova.es/jurisprudencia/JURIDICO/44024/sentencia-ap-cuenca-43-2004-de-26-de-febrero-competencia-en-materia-de-divorcio-de-matrimonio-ec

Ley 34/84. De reforma urgente de la Ley de Enjuiciamiento Civil. Agosto 7 de 1984. BoE N. ${ }^{\circ} 188$.

Ley 1/2000. Ley de Enjuiciamiento Civil. Enero 7 de 2000. BOE N. ${ }^{\circ}$.

Ley 30/1981. Por la que se modifica la regulación del matrimonio en el Código Civil y se determina el procedimiento a seguir en los casos de nulidad, separación, y divorcio. Julio 20 de 1981. воE N. ${ }^{\circ} 172$.

Ley $41 / 2003$. De protección patrimonial de las personas con discapacidad y de modificación del Código Civil, de la Ley de Enjuiciamiento Civil y de la Normativa Tributaria con esta finalidad. Noviembre 18 de 2003. воE N. ${ }^{\circ} 277$.

Ley 13/2005. Por la que se modifica el Código Civil en materia de derecho a contraer matrimonio. Julio 2 de 2005. BOE N. ${ }^{\circ} 157$.

menor se adjudica a la madre, pero el padre tendrá derecho a visita [...] y abonará en concepto de alimentos la cantidad de 30.000 ptas. mensuales". 
Ley 42/2003. De modificación del Código Civil y de la Ley de Enjuiciamiento Civil en materia de relaciones familiares de los nietos con los abuelos. Noviembre $21 \mathrm{de}$ 2003. воE N. ${ }^{\circ} 280$.

Ley Orgánica 11/2003. De medidas concretas en materia de seguridad ciudadana, violencia doméstica e integración social de los extranjeros. Septiembre 29 de 2003. BOE N. ${ }^{\circ} 234$.

Luis Riesgo. Divorcio ¿SOlución O PROBlema?: VEINTE AÑOS DE DIVORCIO, 1981-2001. Comercial. (2001).

Ministerio de Justicia. Memoria de la Fiscalía General DEL Estado DEL AÑo 2012. Centro de Estudios Jurídicos. (2012).

Natalia Junquera. Pensión alimentaria hasta los 31. EL PAís. Octubre 31 de 2014. Disponible en http:// politica.elpais.com/politica/2014/10/30/actualidad/1414708075_972310.html

Patricia Panero Oria. El concubinato romano como antecedente de las actuales parejas de hecho. Revista INTERnacional de Derecho Romano 5. Págs. 92-125.

Real Decreto de 3 de febrero de 1881. [Ministerio de Gracia y Justicia]. Promulgación de la Ley de Enjuiciamiento Civil. Febrero 5 de 1881 . Gaceta N. ${ }^{\circ} 36$.
Rosario Fernández Valpuesta. La encrucijada de la Familia: Entre la realidad social y el Derecho. Boletín MexiCANo de Derecho Comparado 9. 2004. Págs. 89-120.

Tribunal Constitucional. Sentencia 241/200o. (Octubre 16 de 2000).

Tribunal Constitucional. Sentencia 4/2001. (Enero 15 de 2001).

Tribunal Supremo. Sentencia 1084/2000. (Noviembre 22 de 2000).

Tribunal Supremo. Sentencia 138/2015. (M. P. Rafael Sarazá Jimena; Marzo 24 de 2015). Disponible en http://s01. s3c. es/imag/doc/2015-04-16/STSs_ClausulaSuelo.pdf

vVAA. El Ts reitera que la obligación de satisfacer un "mínimo vital" al menor solo puede suspenderse en supuestos muy excepcionales. Noticias Jurídicas. Marzo 7 de 2015. Disponible en http://noticias.juridicas.com/ juris/594-el-ts-reitera-que-la-obligacion-de-satisfacer-un-minimo-vital-al-menor-solo-puede-suspenderse-en-supuestos-muy-excepcionales.html 